\title{
Impacts of You Gui Wan on the expression of estrogen receptors and angiogenic factors in OVX-rat vagina: A possible mechanism for the trophic effect of the formula on OVX-induced vaginal atrophy
}

\author{
QIAO-ZHI YIN ${ }^{1}$, HUA LU $^{1}$, LI-MIN LI ${ }^{2}$, SHANG-MIAN YIE ${ }^{1}$, XIANG HU $^{1}$, ZHI-BIN LIU ${ }^{3}$, \\ XIAO ZHENG ${ }^{1}$, SHENG CAO ${ }^{1}$ and ZOU-YING YAO ${ }^{1}$ \\ ${ }^{1}$ Department of Gynecology and Obstetrics, Second Medical College/Teaching Hospital, \\ Chengdu University of Traditional Chinese Medicine, Chengdu, Sichuan 610048; \\ ${ }^{2}$ Sichuan Academy of Chinese Medicine Sciences, Chengdu, Sichuan 610041; \\ ${ }^{3}$ Key Laboratory of Bio-resources and Eco-environment of Ministry of Education, \\ College of Life Science, Sichuan University, Chengdu, Sichuan 610064, P.R. China
}

Received May 23, 2013; Accepted August 8, 2013

DOI: $10.3892 / \mathrm{mmr} .2013 .1670$

\begin{abstract}
The administration of You Gui Wan (YGW) decoction has been observed to improve vaginal atrophy induced by ovariectomy (OVX) in rats. The aim of the current study was to explore the possible mechanisms underlying this effect. Following OVX, 37 Sprague Dawley female rats were randomly divided into three groups which were orally administered with YGW decoction, saline or estrogen for 11 weeks. In parallel with this, 19 normal and 17 rats with sham-surgery were used as controls. The effects of these treatments on estrogen receptors (ER) and various angiogenic factors, including vascular endothelial growth factor (VEGF), vascular endothelial growth factor receptor-1 (VEGFR-1), angiopoietin (Ang)1 and 2 and basic fibroblast growth factor (bFGF) in the vagina were compared using immunohistochemistry or quantitative polymerase chain reaction (qPCR). OVX was found to induce significant vaginal atrophy and decrease the expression of ER and various angiogenic factors when compared with the normal and sham-surgery animals (all $\mathrm{P}<0.05)$. Estrogen replacement and the administration of YGW decoction reversed the vaginal atrophic process. The hormonal replacement and YGW treatment recovered the protein expression of ER- $\alpha$
\end{abstract}

Correspondence to: Professor Hua Lu, Department of Gynecology and Obstetrics, Second Medical College/Teaching Hospital, Chengdu University of Traditional Chinese Medicine, Fourth Segment, 15 Remin Nanlu Road, Chengdu, Sichuan 610048, P.R. China E-mail: kjclh@126.com

Key words: You Gui Wan, ovariectomy, rat, estrogen receptor- $\alpha$, estrogen receptor- $\beta$, angiogenic factors and $-\beta$, VEGF and VEGFR- 1 and the mRNA levels of ER- $\alpha$, VEGF, VEGFR-1, Ang1 and 2, and bFGF when compared with OVX-rats with saline, normal and sham-surgery treatments (all $\mathrm{P}<0.05$ ). Thus, it may be concluded that a possible mechanism underlying the effect of YGW on OVX-induced vaginal atrophy may be the upregulated expression of ER and various angiogenic factors in the vaginal tissue.

\section{Introduction}

The majority of females in their late 40 s or early 50 s may experience a variety of menopausal symptoms that include vaginal atrophy and changes in uterine size and lining. Although western medicine treats menopausal symptoms with various forms of hormone replacement therapy (HRT), a number of females may elect to forgo these therapies due to a number of side effects (1). However, Traditional Chinese Medicine (TCM) has been used to relieve menopausal symptoms for centuries with little adverse effects (2-5).

You Gui Wan (YGW) is a classical herbal formula in TCM which has been used clinically in menopausal females with Yang deficiency. In a previous study, YGW was observed to reverse the atrophic effect of ovariectomy (OVX) in rat vaginal plica and blood vessels in the lamina propria with little adverse effect on endometrial hyperplasia (6). The results suggested that YGW may be used as an alternative to HRT in the management of menopausal vaginal atrophy. However, the molecular mechanisms underlying the effect of YGW remain unknown.

In a previous study, the major effect of YGW was shown to recover the number of vaginal blood vessels which were reduced by OVX (6), indicating that YGW may alter angiogenesis regulators in the vaginal tissue in vivo. It is well established that angiogenesis, the formation of new blood vessels from existing blood vessels, involves a number of processes, including the degradation of existing vascular basement membrane, the 
proliferation and migration of endothelial cells (ECs) into tubular structures and the formation of a new matrix around neovessels (7). Angiogenesis also requires a number of angiogenic proteins, including several growth factors such as basic fibroblast growth factor (bFGF), vascular endothelial growth factor (VEGF) and angiopoietin (Ang)1 and 2.

Estrogen is key in maintaining uterine and vaginal health. Estrogen produces its effects by binding to estrogen receptors (ER) in the reproductive organs. It has been reported that estradiol increases the extracellular levels of VEGF in breast cancer in vivo, which suggest that VEGF expression in the breast is, at least in part, modulated by ER for which the VEGF gene is a target (7). In cultured human endometrial fibroblasts (8) and a number of endometrial cancer cell lines (9), estrogens increase bFGF mRNA or proteins. Furthermore, the regulation of Ang1 and 2 is associated with VEGF expression within the microenvironment of angiogenic blood vessels to ensure precise and stage-appropriate angiogenic signals to ECs $(10,11)$.

In addition, YGW has been shown to be capable of recovering the expression of ER, despite having no significant effect on estradiol production (6). Therefore, we hypothesized that there may be specific components in the YGW decoction that produce an estrogenic-like activity to reverse the atrophic effect caused by OVX (6). In the current study, YGW was hypothesized to upregulate angiogenic factors to reverse the atrophic effect of OVX through the recovery of ER expression and the cooperative interactions of specific angiogenic factors.

To investigate this hypothesis, the effects of YGW on the expression of ER, VEGF, vascular endothelial growth factor receptor-1 (VEGFR-1), bFGF and Ang1 and 2 were investigated in the vagina following long-term (11 weeks) oral administration of YGW decoctions in OVX-rats and the results were compared with OVX-rats treated with estrogen replacement or saline.

\section{Materials and methods}

Materials. YGW was obtained from the Beijing Tongrentang Co., Ltd. (Beijing, China) with the herbal medicine license no. Z23020593. YGW is composed of nine herbal ingredients (12), including Radix rehmanniae preparata, Fructus corni officinalis, Fructus lycii, Colla cornus cervi, Cuscuta chinensis LAM, Eucommia ulmoides, Radix angelicae sinensis, Cinnamomum and Radix aconiti lateralis preparata. Decoctions of the formula were prepared using standard methods (13), diluted with saline and stored at $4^{\circ} \mathrm{C}$ prior to use. Premarin was purchased from Wyeth Pharmaceuticals (Rouses Point, NY, USA).

Animals. The Animal Care and Use Committee at the Chengdu University of Traditional Chinese Medicine approved the study and all associated procedures as protocol no. 30472225 .

In total, 73 Sprague Dawley female rats, aged 12-14 weeks, with an average weight of $230 \pm 30 \mathrm{~g}$, were used as the test subjects. The rats were supplied by the Laboratory Animal Service Center at the Chengdu University of Traditional Chinese Medicine and maintained in an air-conditioned room with a temperature of $22-25^{\circ} \mathrm{C}$, a humidity level of $45-65 \%$
Table I. Source and dilution of primary antibodies used in the current study.

\begin{tabular}{lllc}
\hline Antibody & Clone & Manufacturer & Dilution \\
\hline ER- $\alpha$ & 1D5 & ZSGB Bio & $1: 100$ \\
ER- $\beta$ & B68 & ZSGB Bio & $1: 200$ \\
VEGF & VG1 & Maixin Bio & $1: 400$ \\
VEGFR-1 & Polyclone & Sigma-Aldrich & $1: 100$ \\
\hline
\end{tabular}

ER, estrogen receptor; VEGF, vascular endothelial growth factor; VEGFR-1, vascular endothelial growth factor receptor-1.

and a 12-h light/dark cycle. The animals were randomly divided into five groups: i) ovariectomized-treated with YGW decoctions $(\mathrm{n}=13)$; ii) ovariectomized-treated with saline $(\mathrm{n}=12)$; iii) ovariectomized-treated with Premarin ( $\mathrm{n}=12)$; iv) a sham-surgery in diestrus $(\mathrm{n}=17)$; and $\mathrm{v})$ a normal control in diestrus $(\mathrm{n}=19)$. The reproductive status of the animals was determined by a daily vaginal lavage performed $\sim 2 \mathrm{~h}$ following lights on for all rat groups using traditional nomenclature for the estrous and diestrus stages (14).

OVX/sham-surgery and treatment. Procedures for OVX and sham-surgery were described previously (6). Briefly, rats in diestrus were anesthetized intraperitoneally with a mixture of ketamine hydrochloride $(73 \mathrm{mg} / \mathrm{kg})$ and xylazine $(8.8 \mathrm{mg} / \mathrm{kg})$. Surgery was performed using aseptic precautions on a heating pad to maintain a body temperature of $37^{\circ} \mathrm{C}$. For OVX, the ovaries were removed by slicing through the tissue on the rostral side of each hemostat, while for sham-surgery, four similarly sized sections of fat were sliced from this segment. Following determination that there was no bleeding in the abdominal cavity, the wound was closed. The rats were closely observed during the post-surgical period for potential complications of which none occurred. OVX was confirmed by daily vaginal lavages that consisted of leukocytes indicative of constant diestrus. Constant diestrus continued until saline, YGW treatment or estrogen replacement which were performed $\sim 2$ weeks later.

For groups i)-iii), the rats were orally administered with saline-diluted YGW decoctions (preparation: saline, $1: 1 \mathrm{v} / \mathrm{v}$ and $1 \mathrm{ml} / 100 \mathrm{~g}$ body weight); saline $(1 \mathrm{ml} / 100 \mathrm{~g}$ body weight); and Premarin $(62.5 \mathrm{mg} / 100 \mathrm{~g}$ body weight) for 11 weeks, respectively. For groups iv) and v), the rats were orally administered with saline only. On the final day of oral administration, the animals were sacrificed and their vaginas were saved for histological examination, as well as immunohistochemical and quantitative polymerase chain reaction (qPCR) analysis.

Vaginal histological examination. Procedures for vaginal histological examination were described previously (6). Briefly, following fixation of tissue samples in $4 \%$ paraformaldehyde in $0.1 \mathrm{M}$ phosphate buffer $(\mathrm{pH} 7.4)$ for $24 \mathrm{~h}$ at $4^{\circ} \mathrm{C}$, the samples were dehydrated by a routine procedure through graded dilutions of ethanol (70-100\%). Samples were embedded 
Table II. List of the primers used in the qPCR analysis.

\begin{tabular}{|c|c|c|}
\hline Biomarkers & Primers & Amplified size \\
\hline ER- $\alpha$ & $\begin{array}{l}\text { 5'-GCTCTTGGACAGGAACCAGG-3' } \\
\text { 5'-AAGATCTCCACCATGCCCTCT-3' }\end{array}$ & 187 \\
\hline VEGF & $\begin{array}{l}\text { 5'-AGGCCAGCACATAGGAGAGA-3' } \\
\text { 5'-TTTCTTGCGCTTTCGTTTTT-3' }\end{array}$ & 232 \\
\hline VEGFR-1 & $\begin{array}{l}\text { 5'-TGTGTGGCTGCGACACTCTT-3' } \\
\text { 5'-ATAGGGCAGCCGTTCACACT-3' }\end{array}$ & 150 \\
\hline Ang1 & $\begin{array}{l}\text { 5'-GACAAGACCCCCACGTGTCT-3' } \\
\text { 5'-CCAGATCAGGTGGTGGCATT-3' }\end{array}$ & 150 \\
\hline Ang2 & $\begin{array}{l}\text { 5'-GGTCAAGGCCTACTGTGACATG-3' } \\
\text { 5'-TCGTTGCCCAGCCAATACTC-3' }\end{array}$ & 150 \\
\hline bFGF & $\begin{array}{l}\text { 5'-GACCCTCACATCAAGCTACAACT-3' } \\
\text { 5'-AAAGAAACACTCATCCGTAACACA-3' }\end{array}$ & 141 \\
\hline GAPDH & $\begin{array}{l}\text { 5'-GAAGGTGAAGGTCGGAGT-3' } \\
\text { 5'-GAAGATGGTGATGGGATTTC-3' }\end{array}$ & 226 \\
\hline
\end{tabular}

in paraffin and $4 \mu \mathrm{m}$ sections were mounted on poly-lysine coated slides. Hematoxylin and eosin (H\&E) staining of the tissue sections was used for histological examination and the results were summarized as a mean of three regions observed.

Immunohistochemistry. Immunostaining of ER- $\alpha$ and $-\beta$, VEGF and VEGFR-1 in vaginal tissue was performed using immunohistochemical kits from Abcam (Cambridge, UK) according to the manufacturer's instructions. Briefly, deparaffinization of tissue sections was performed similar to the aforementioned H\&E staining. Following deparaffinization, an antigen retrieval treatment was performed at $120^{\circ} \mathrm{C}$ (autoclave) for $5 \mathrm{~min}$ in a $10 \mathrm{nmol} / 1$ sodium citrate buffer (pH 6.0). Endogenous peroxidase activity was blocked using a $0.03 \%$ hydrogen peroxide solution containing sodium azide at room temperature for $30 \mathrm{~min}$. Then, anti-ER- $\alpha$ and $-\beta$, VEGF and VEGFR- 1 antibodies were incubated at $4^{\circ} \mathrm{C}$ overnight. Primary antibody sources and concentrations are listed in Table I. Subsequently, thorough washing in a $0.01 \mathrm{M}$ phosphate-buffered saline solution was performed. Binding sites of the primary antibody were visualized using a secondary antibody conjugated with horseradish peroxidase and 3,3'-diaminobenzidine substrate. Sections were then faintly counterstained with hematoxylin and mounted with glycerol gelatin. Negative controls were achieved by the omission of the primary antibodies.

Sections were analyzed using an Automated Cellular Imaging System (ACIS; DAKO, Carpinteria, CA, USA). ACIS calculated the average intensity within 12 representative regions per slide as a measure of the integrated optical density (IOD). Scores for the highest and lowest regions for each slide were excluded and the average region score was calculated from the remaining 10 regions. For comparison purposes, the IOD value was normalized to the entire measured area by calculating IOD/0.25 $\mathrm{mm}(2,15)$.

$q P C R$. To assess the mRNA expression of ER- $\alpha, \mathrm{VEGF}$, VEGFR-1, Ang1 and 2 and bFGF, qPCR was used as previously described (16). Briefly, total RNA was extracted using TRIzol reagents (Invitrogen Life Technologies, Carlsbad, CA, USA) and complementary DNA was prepared from the total RNA using oligo primers and Moloney murine leukemia virus reverse transcriptase (Applied Biosystems, Inc., Foster City, CA, USA). qPCR was performed with the SYBR-Green mix (Applied Biosystems, Inc.) on an ABI Prism 7900 sequence detector (Life Technologies, Carlsbad, CA, USA). Specific primers for ER- $\alpha$, VEGF, VEGFR-1, Ang1 and 2, bFGF and glyceraldehyde 3-phosphate dehydrogenase (GAPDH) are listed in Table II. For each PCR product, the melting curve was determined using the comparative threshold cycle number $\left(2^{-\Delta \Delta \mathrm{Ct}}\right)$ method, with the results presented as fold change in the expression of ER- $\alpha$, VEGF, VEGFR-1, Ang1, and 2 and bFGF relative to OVX-rats treated with saline (17).

Data analysis. Statistical analysis was performed using the SPSS software package (SPSS Inc., Chicago, IL, USA). Since the data did not violate assumptions of homogeneity of variance and normal distribution, differences in all morphological and histological parameters of the vagina, as well as the IOD scores and $2^{-\Delta \Delta \mathrm{Ct}}$ method among the experimental groups, were compared using the one-way analysis of variance. If significance was found in the analysis, the data underwent post-hoc comparisons. $\mathrm{P}<0.05$ was considered to indicate a statistically significant difference. 
Table III. Effects of Premarin and YGW on the expression of ER, VEGF and VEGFR-1.

\begin{tabular}{lccccc}
\hline Groups & $\mathrm{n}$ & $\begin{array}{c}\text { ER- } \alpha \text { IOD value, } \\
\text { mean } \pm \mathrm{SE}\end{array}$ & $\begin{array}{c}\text { ER- } \beta \text { IOD value, } \\
\text { mean } \pm \mathrm{SE}\end{array}$ & $\begin{array}{c}\text { VEGF IOD value, } \\
\text { mean } \pm \text { SE }\end{array}$ & $\begin{array}{c}\text { VEGFR-1 IOD value, } \\
\text { mean } \pm \text { SE }\end{array}$ \\
\hline Normal & 17 & $483.72 \pm 65.66$ & $557.06 \pm 53.40$ & $483.72 \pm 65.66$ & $557.06 \pm 53.40$ \\
Sham-surgery & 19 & $507.10 \pm 53.71$ & $549.70 \pm 44.39$ & $507.10 \pm 53.71$ & $549.70 \pm 44.39$ \\
OVX-rats with saline & 12 & $340.25 \pm 35.03^{\mathrm{a}}$ & $352.08 \pm 69.68^{\mathrm{a}}$ & $340.25 \pm 35.03^{\mathrm{a}}$ & $352.08 \pm 69.68^{\mathrm{a}}$ \\
OVX-rats with Premarin & 12 & $506.67 \pm 43.32$ & $550.75 \pm 46.78$ & $506.67 \pm 43.32$ & $550.75 \pm 46.78$ \\
OVX-rats with YGW & 13 & $470.08 \pm 64.72$ & $411.00 \pm 98.54$ & $470.08 \pm 64.72$ & $411.00 \pm 98.54$ \\
\hline
\end{tabular}

${ }^{\mathrm{a}} \mathrm{P}<0.05$ when comparing OVX-rats with saline or YGW or Premarin to normal and sham-surgery controls. YGW, You Gui Wan; ER, estrogen receptor; VEGF, vascular endothelial growth factor; VEGFR-1, vascular endothelial growth factor receptor-1; IOD, integrated optical density; SE, standard error; OVX, ovariectomy.
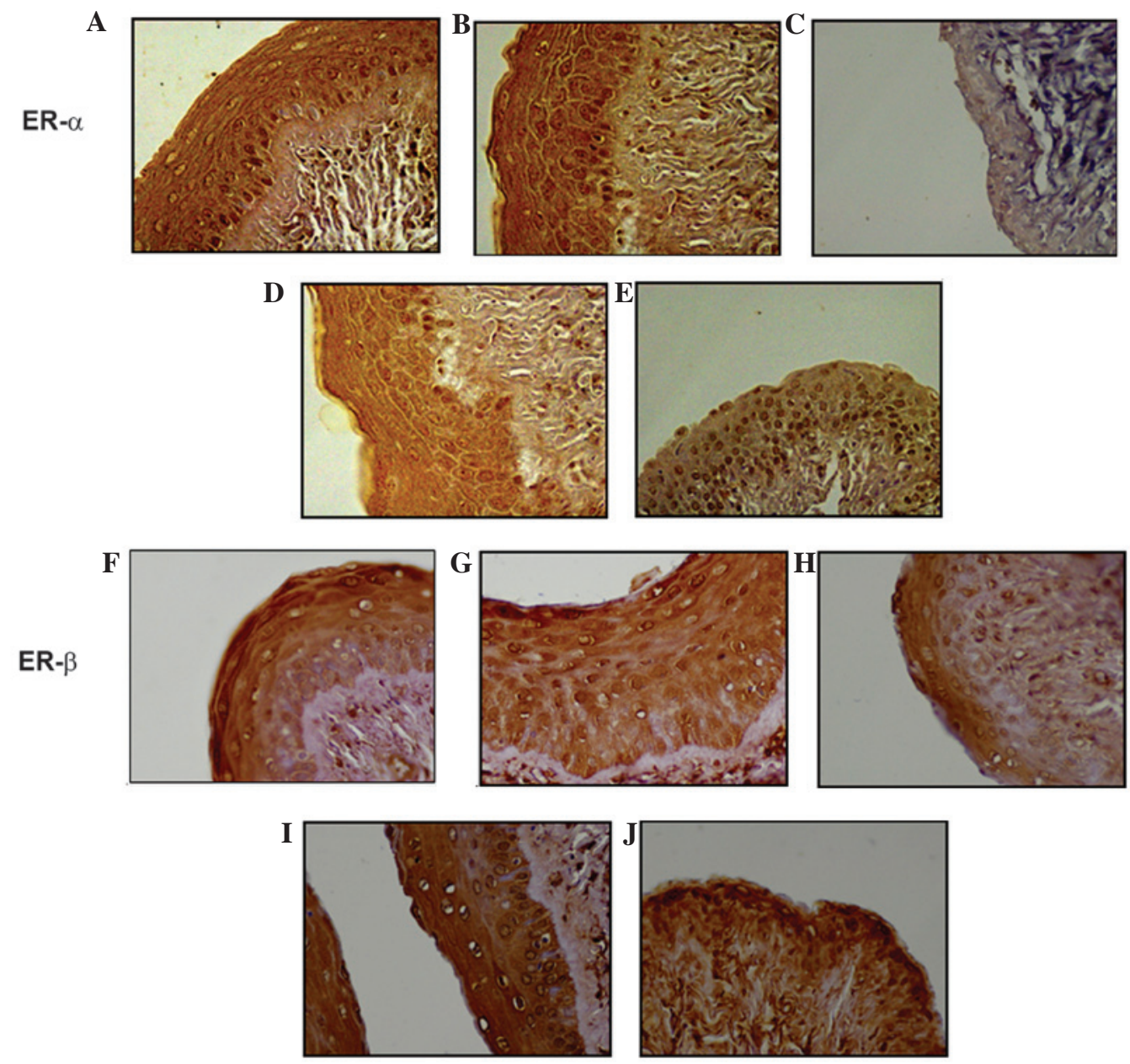

Figure 1. Immunostaining detection of the expression of ER- $\alpha$ and $-\beta$ in rat vaginal tissue. (A)-(E) ER- $\alpha$ expression in the vagina of normal rats at (A) diestrus; (B) sham-surgery; (C) OVX- with saline; (D) OVX- with Premarin and (E) OVX- with YGW, respectively. (F)-(J) ER- $\beta$ expression in the vagina of normal rats at (F) diestrus; (G) sham-surgery at diestrus; (H) OVX- with saline; (I) OVX- with Premarin and (J) OVX- with YGW, respectively. Notably, OVX markedly reduced ER expression when compared with normal and sham-surgery animals. However, estrogen-replacement and YGW decoction reversed the effects of OVX. Magnification, x200. ER, estrogen receptor; OVX, ovariectomy; YGW, You Gui Wan.

\section{Results}

Effect of YGW on vaginal atrophy in OVX-rats. All parameters of vaginal histomorphology in OVX-rats treated with saline were significantly lower than those in normal and sham-surgery animals (all $\mathrm{P}<0.05)$. In the group with Premarin replacement, all the parameters of the vagina in OVX-rats were reversed to the level of normal and sham-surgery controls. Treatment with YGW decoctions on OVX-rats reversed the effect of OVX on the number of vaginal fold and blood vessels in the lamina propria. These results were in agreement with a previous report (6). 

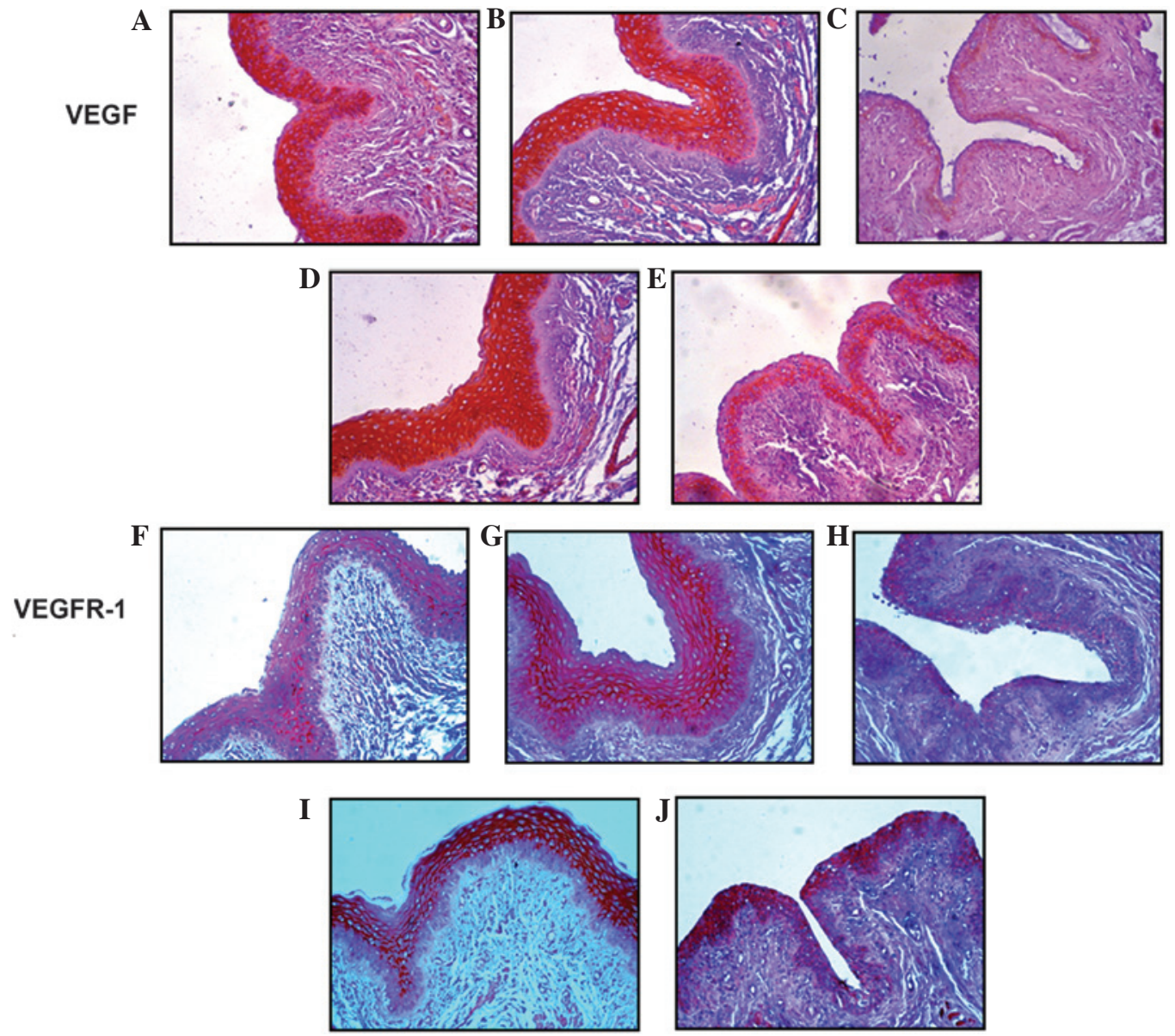

Figure 2. Immunostaining detection of expression of VEGF and VEGFR-1 in rat vaginal tissue. (A)-(E) VEGF expression in the vagina of normal rats at (A) diestrus; (B) sham-surgery; (C) OVX- with saline; (D) OVX- with Premarin and (E) OVX- with YGW, respectively. (F)-(J) VEGFR-1 expression in the vagina of normal rats at (F) diestrus; (G) sham-surgery at diestrus; (H) OVX-with saline; (I) OVX-with Premarin and (J) OVX-with YGW, respectively. Notably, OVX markedly reduced estrogen receptor expression when compared with normal and sham-surgery animals. However, estrogen-replacement and YGW decoction reversed the effects of OVX. Magnification, x200. VEGF, vascular endothelial growth factor; VEGFR-1, vascular endothelial growth factor receptor-1; OVX, ovariectomy; YGW. You Gui Wan.

Effects of $Y G W$ on protein expression of ER, VEGF and $V E G F R-1$ in OVX-rats. ER- $\alpha$ or $-\beta$ immunostaining was primarily restricted to the nucleus of the cells, while VEGF and VEGFR-1 were observed in membrane and cytoplasmic staining. The effects of OVX, estrogen replacement and the administration of YGW on the protein expression of ER- $\alpha$ or $-\beta$, VEGF and VEGFR-1 in the rat vagina are summarized in Table III. In OVX-rats, OVX decreased the expression of ER- $\alpha$ or $-\beta$, VEGF and VEGFR-1 when compared with normal and sham-surgery animals $(\mathrm{P}<0.05)$. Estrogen replacement and YGW treatment recovered OVX-induced suppression when compared with normal and sham-surgery controls. Fig. 1 shows representative samples of the effects of OVX, estrogen replacement and the administration of YGW on the expression of ER- $\alpha$ or $-\beta$. Fig. 2 shows representative samples of the effects of OVX, estrogen replacement and the administration of YGW on the expression of VEGF and VEGFR-1.

Effects of YGW on the transcription of ER- $\alpha, V E G F, V E G F R-1$, Angl and 2 and $b F G F$. Comparisons of gene transcription of ER- $\alpha$, VEGF, VEGFR-1, Ang1 and 2 and bFGF in vaginal tissue among the groups are shown in Fig. 3. The levels of ER- $\alpha$ mRNA expression in normal, sham-surgery, OVX- with
Premarin and OVX-rats with YGW were 1.83, 1.54, 1.53 and 1.36 times higher compared with OVX-rats with saline, respectively ( $\mathrm{P}<0.05$; Fig. 3A). Moreover, mRNA expression of VEGF, bFGF and Ang1 in normal, sham-surgery, OVX- with Premarin and OVX- with YGW rats were also significantly higher compared with OVX-rats with saline (VEGF mRNA were 4.21, 3.54, 3.20 and 5.92 times higher; bFGF mRNA were 1.97, 1.74, 2.02 and 1.92 times higher and Ang1 mRNA were $2.73,2.50,5.50$ and 4.46 times higher, respectively; all $\mathrm{P}<0.05$; Fig. 3B, D and E). Notably, the VEGF mRNA expression in the vaginal tissue of OVX-rats treated with YGW was significantly higher compared with the estrogen replacement group (3.20 for the estrogen replacement group vs. 5.92 for the OVX-rats treated with YGW; P<0.05; Fig. 3B). VEGFR-1 mRNA expression in normal, sham-surgery and OVX-rats with Premarin were 1.39, 1.47 and 1.34 times higher compared with OVX-rats with saline, respectively $(\mathrm{P}<0.05)$, but no significant difference was found between OVX-rats with YGW and OVX-rats with saline (Fig. 3C). Ang-2 mRNA expression in normal rats was similar to that of the OVX-rats with saline (0.94). However, for sham-surgery and OVX-rats with Premarin or YGW, Ang2 mRNA expression was $1.25,2.44$ or 2.32 times higher compared with the OVX- rats with saline 
A

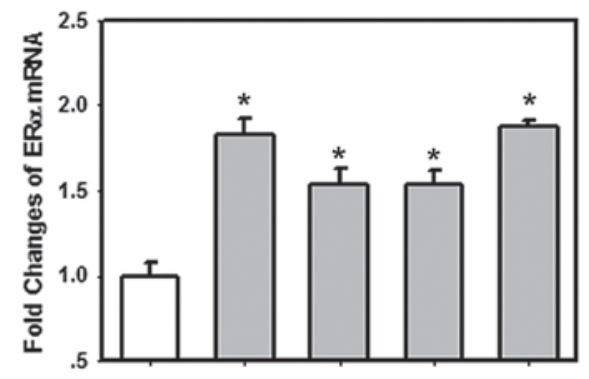

C

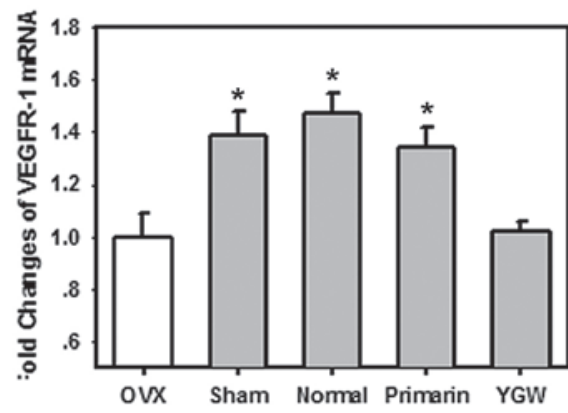

$\mathbf{E}$

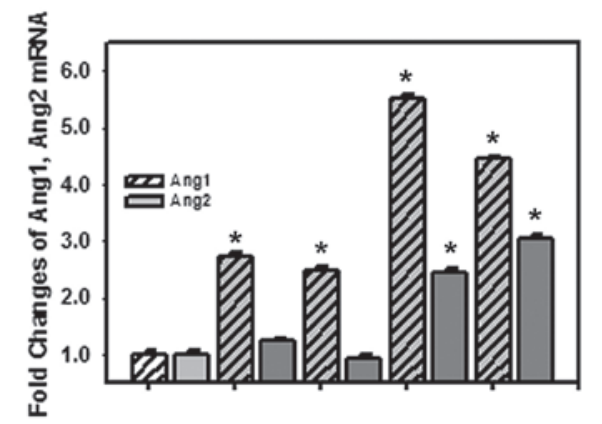

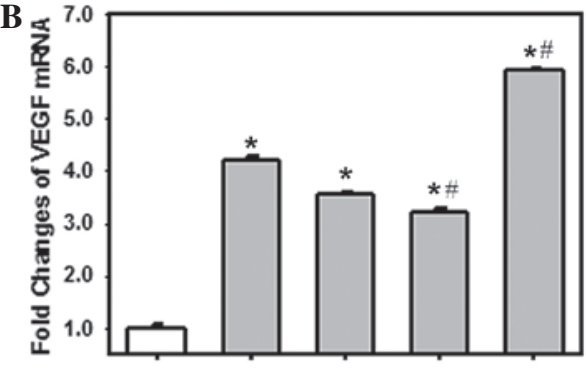
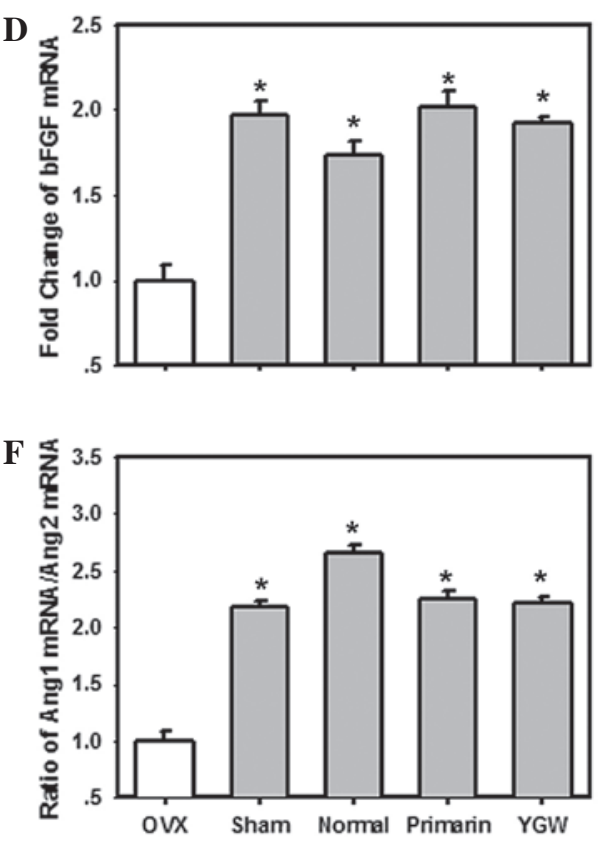

Figure 3. Effects of YGW on the mRNA levels of (A) ER- $\alpha$; (B) VEGF; (C) VEGFR-1; (D) bFGF; and (E) Ang1 and 2 in rat vaginal tissues by real-time polymerase chain reaction. Fold changes $\left(2^{-\Delta \Delta C t}\right)$ in the expression of these angiogenic factors were calculated from the $\Delta \mathrm{Ct}$ values for the angiogenic factors, obtained following the subtraction of Ct values for GAPDH (internal control), relative to those for OVX-rat with saline. (F) Ratios of Ang1 mRNA to Ang2 mRNA in normal, sham-surgery, OVX- with saline, OVX- with Premarin and OVX-rats with YGW are shown. Vertical error bars indicate \pm standard error. ${ }^{*} \mathrm{P}<0.05$ vs. OVX-rats with saline and ${ }^{*} \mathrm{P}<0.05$ for Premarin- vs. YGW-treated OVX-rats. YGW, You Gui Wan; ER, estrogen receptor; VEGF, vascular endothelial growth factor; VEGFR-1, vascular endothelial growth factor receptor-1; bFGF, basic fibroblast growth factor; Ang, angiopoietin; GAPDH, glyceraldehyde 3-phosphate dehydrogenase; OVX, ovariectomy.

(P<0.05; Fig. 3E). The ratios of Ang1 and 2 mRNA expression in normal, sham-surgery and OVX-rats with Premarin or YGW were 2.18, 2.66, 2.25 and 2.22 times higher compared with the OVX-rats with saline ( $\mathrm{P}<0.05$; Fig. 3F).

\section{Discussion}

In the current study, the effects of the administration of YGW decoctions in reversing rat vaginal atrophy caused by OVX were confirmed and were in agreement with a previous study (6). The major observations of the present study may be summarized as follows: i) OVX reduces the expression of vaginal ER and specific angiogenic factors in vaginal tissue; ii) estrogen replacement may recover OVX effects and iii) YGW decoction may also recover expression of ER and specific angiogenic factors. The upregulation effects of YGW were not implemented by endogenous estrogen production as YGW had no significant effect on the circulating estrogen levels reduced by OVX (6).

The promotion of angiogenesis by estrogen replacement may be via ER signaling pathways since reduced estrogen production following OVX decreased the number of ER in the blood vessel walls, as well as changes in the post-ER signaling mechanisms (18). ER has been observed to mediate angiogenesis through classical genomic and rapid non-genomic mechanisms (19-21).

How YGW implements its effects on the various angiogenic factors remains to be determined as the chemical profile of YGW is not yet known. However, there may be one or more main active components in each of the herb in YGW according to published data. The primary active component of Radix rehmanniae reparata has been reported to be oligosaccharides (22). In Fructus corni officinalis, the primary active components are morroniside, loganin and gallic acid (23). In Fructus lycii, it is Lycium Barbarum polysaccharide (24). For Cuscuta chinensis LAM, the component is hypothesized to be flavones glycoside (25) and for Eucommia ulmoides, the components consist of acidic polysaccharide metal salt and glucosidic metal salt (26). Radix angelicae sinensis is reported to contain phthalides, organic acids and their esters (27) while Cinnamomum has phenylpropanoids cinnamaldehyde and eugenol (28). Radix aconiti lateralis preparata is reported to contain benzoylmesaconine (29). 
A number of these active components have been hypothesized to possess estrogenic activity. For example, flavones glycoside, the component of Cuscuta chinensis LAM, may be a phytoestrogen (30). A number of phytoestrogens have been defined as selective estrogen receptor modulators. These substances may also provide cardiovascular benefits, including regulation of ECs proliferation, differentiation, adhesion, migration and kinase activation through interaction with ER $(31,32)$. Other components may directly exert angiogenic activity. For instance, morroniside, one of the active components of Fructus corni officinalis, may exert a beneficial effect on preventing diabetic angiopathies (33). However, accumulated clinical observations have concluded that the herbal formula of YGW is more effective than any single herb since the formula may possess much broader actions. Therefore, the effects of the YGW herbs may be a synthetic action of all main constituents rather than a single component.

Although YGW and Premarin may reverse the expression of ER and specific angiogenic factors, varying potency was observed in the current study. For example, VEGF mRNA expression in the vaginal tissue of OVX-rats treated with YGW was higher compared with that of the estrogen replacement group, while YGW had no significant effect on the repression of VEGFR-1 mRNA. It is possible that YGW may contain a number of components that may directly affect VEGF expression other than via ER signaling pathways. These observations also suggest that YGW may have stronger effects on angiogenesis since VEGF is a critical and specific factor stimulating physiological and pathological angiogenesis (34). However, to verify this, further studies are required in the future.

In conclusion, the current observations indicate that YGW, similar to estrogen replacement, may recover the expression of ER and various angiogenic factors in the vaginal tissue of OVX-rats. The induction of the expression of various angiogenic factors by the herbal formula was, at least in part, mediated through the activation of the ER pathways. The current study provides an explanation for the underlying mechanisms of YGW to reverse vaginal atrophy induced by OVX, although future research is required to elucidate the herb-induced signaling pathways. These data may aid in the development of improved approaches to stimulate angiogenesis, as well as to provide an improved understanding of the potential health benefits of the herbal agents of YGW in treating vaginal atrophy induced by OVX or menopause.

\section{Acknowledgements}

This study was supported by grants from the National Basic Research Program in China (973 Plan, no. 2010CB530403 and 2010CB530400).

\section{References}

1. Anderson GL,Limacher M, Assaf AR, et al: Effects of conjugated equine estrogen in postmenopausal women with hysterectomy: the Women's Health Initiative randomized controlled trial. JAMA 291: 1701-1712, 2004.

2. Haines CJ, Lam PA, Chung TK, Cheng KF and Leung PC: A randomized, double-blind, placebo-controlled study of the effect of a Chinese herbal medicine preparation (Dang Gui Buxue Tang) on menopausal symptoms in Hong Kong Chinese women. Climacteric 11: 244-251, 2008.
3. Chan CC, Lau WN, Chiu SP, Chen LC, Choi WK and Tang GW: A pilot study on the effects of a Chinese herbal preparation on menopausal symptoms. Gynecol Endocrinol 22: 70-73, 2006.

4. Kwee SH, Tan HH, Marsman A and Wauters C: The effect of Chinese herbal medicines (CHM) on menopausal symptoms compared to hormone replacement therapy (HRT) and placebo. Maturitas 58: 83-90, 2007.

5. Zell B, Hirata J, Marcus A, Ettinger B, Pressman A and Ettinger KM: Diagnosis of symptomatic postmenopausal women by traditional Chinese medicine practitioners. Menopause 7: 129-134, 2000.

6. Hu X, Wang J, Yin QZ, Lu H and Yie SM: You Gui Wan can reverse atrophic effect of ovariectomy on rat vaginal fold and blood vessels in the lamina propria. Biol Pharm Bull 34: 1808-1814, 2011.

7. Applanat MP, Buteau-Lozano H, Herve MA and Corpet A: Vascular endothelial growth factor is a target gene for estrogen receptor and contributes to breast cancer progression. Adv Exp Med Biol 617: 437-444, 2008

8. Fujimoto J, Hori M, Ichigo S and Tamaya T: Ovarian steroids regulate the expression of basic fibroblast growth factor and its mRNA in fibroblasts derived from uterine endometrium. Ann Clin Biochem 34: 91-96, 1997.

9. Presta M: Sex hormones modulate the synthesis of basic fibroblast growth factor in human endometrial adenocarcinoma cells: implications for the neovascularization of normal and neoplastic endometrium. J Cell Physiol 137: 593-597, 1988.

10. Hangai M, Murata T, Miyawaki N, Spee C, Lim JI, He S, Hinton DR and Ryan SJ: Angiopoietin-1 upregulation by vascular endothelial growth factor in human retinal pigment epithelial cells. Invest Ophthalmol Vis Sci 42: 1617-1625, 2001.

11. Fiedler U and Augustin HG: Angiopoietins: a link between angiogenesis and inflammation. Trends Immunol 27: 552-558, 2006.

12. Zhou J and Qu F: Treating gynaecological disorders with traditional Chinese medicine: a review. Afr J Tradit Complement Altern Med 6: 494-517, 2009

13. Sze SC, Tong Y, Zhang YB, Zhang ZJ, Lau AS, Wong HK, Tsang KW and Ng TB: A novel mechanism: Erxian Decoction, a Chinese medicine formula, for relieving menopausal syndrome. J Ethnopharmacol 123: 27-33, 2009.

14. Becker JB, Arnold AP, Berkley KJ, Blaustein JD, Eckel LA, Hampson E, Herman JP, Marts S, Sadee W, Steiner M, et al: Strategies and methods for research on sex differences in brain and behavior. Endocrinology 146: 1650-1673, 2005.

15. Oberholzer M, Ostreicher M, Christen $\mathrm{H}$ and Brühlmann $\mathrm{M}$ : Methods in quantitative image analysis. Histochem Cell Biol 105: 333-355, 1996

16. Yie SM, Li LH, Li GM, Xiao R and Librach CL: Progesterone enhances HLA-G gene expression in JEG-3 choriocarcinoma cells and human cytotrophoblasts in vitro. Hum Reprod 21: 46-51, 2006.

17. Livak KJ and Schmittgen TD: Analysis of relative gene expression data using real-time quantitative PCR and the 2(-Delta DeltaC(T)) Method. Methods 25: 402-408, 2001.

18. Masood DE, Roach EC, Beauregard KG and Khalil RA: Impact of sex hormone metabolism on the vascular effects of menopausal hormone therapy in cardiovascular disease. Curr Drug Metab 11: 693-714, 2010.

19. Losordo DW and Isner JM: Estrogen and angiogenesis: A review. Arterioscler Thromb Vasc Biol 21: 6-12, 2001.

20. Kim KH, Moriarty K and Bender JR: Vascular cell signaling by membrane estrogen receptors. Steroids 73: 864-869, 2008.

21. Kim-Schulze S, McGowan KA, Hubchak SC, Cid MC, Martin MB, Kleinman HK, Greene GL and Schnaper HW: Expression of an estrogen receptor by human coronary artery and umbilical vein endothelial cells. Circulation 94: 1402-1407, 1996.

22. Liu WX, Lu YW, Du HT and Wu ZZ: Pharmacological actions of Radix Rehmanniae and its active components: research advances. J Int Pharm Res 36: 277-280, 2009.

23. Wang SF, Chen XG, Hu ZD and Ju Y: Analysis of three effective components in Fructus corni and its preparations by micellar electrokinetic capillary chromatography. Biomed Chromatogr 17: 306-311, 2003.

24. Li SY, Yang D, Yeung CM, Yu WY, Chang RC, So KF, Wong D and Lo AC: Lycium barbarum polysaccharides reduce neuronal damage, blood-retinal barrier disruption and oxidative stress in retinal ischemia/reperfusion injury. PLoS One 6: e16380, 2011. 
25. Jin X,Li J and Yan M: Flavonoids in the seed of Cuscuta chinensis Lam. Zhongguo Zhong Yao Za Zhi 17: 292-294, 1992 (In Chinese).

26. Deyama T, Nishibe S and Nakazawa Y: Constituents and pharmacological effects of Eucommia and Siberian ginseng. Acta Pharmacol Sin 22: 1057-1070, 2001.

27. Yi L, Liang Y, Wu $\mathrm{H}$ and Yuan D: The analysis of Radix Angelicae Sinensis (Danggui). J Chromatogr A 1216 1991-2001, 2009.

28. Lockwood GB: Phenylpropanoids from a Nigerian sample of Cinnamomum cassia [proceedings]. J Pharm Pharmacol 31: 8P, 1979.

29. Xie Y, Zhou H, Wong YF, Liu Z, Xu H, Jiang Z and Liu L: An optimized high-performance liquid chromatography (HPLC) method for benzoylmesaconine determination in Radix Aconiti Lateralis Preparata (Fuzi, aconite roots) and its products. Chin Med 3: 6, 2008.

30. Matsuda H, Shimoda H, Morikawa T and Yoshikawa M: Phytoestrogens from the roots of Polygonum cuspidatum (Polygonaceae): structure-requirement of hydroxyanthraquinones for estrogenic activity. Bioorg Med Chem Lett 11: $1839-1842,2001$.
31. Valachovicova T, Slivova V and Sliva D: Cellular and physiological effects of soy flavonoids. Mini Rev Med Chem 4: 881-887, 2004.

32. Kostelac D, Rechkemmer G and Briviba K: Phytoestrogens modulate binding response of estrogen receptors alpha and beta to the estrogen response element. J Agric Food Chem 51: 7632-7635, 2003

33. Xu HQ, Hao HP, Zhang X and Pan Y: Morroniside protects cultured human umbilical vein endothelial cells from damage by high ambient glucose. Acta Pharmacol Sin 25: 412-415, 2004.

34. Zhang K, Lu J, Mori T, Smith-Powell L, Synold TW, Chen S and Wen W: Baicalin increases VEGF expression and angiogenesis by activating the ERR alpha/PGC-1alpha pathway. Cardiovasc Res 89: 426-435, 2011. 